\title{
Production of a newly isolated Paenibacillus polymyxa biocontrol agent using monosodium glutamate wastewater and potato wastewater
}

\author{
Likun $\mathrm{Gu}^{1,2,3}$, Zhihui Bai ${ }^{1, *}$, Bo Jin ${ }^{4}$, Jianyun Zhang ${ }^{2}$, Wenying $\mathrm{Li}^{1}$, \\ Guoqiang Zhuang ${ }^{1}$, Hongxun Zhang ${ }^{1,2}$ \\ 1. Research Centre for Eco-Environmental Sciences, Chinese Academy of Sciences, Beijing 100085, China. E-mail: gulikun-rcees@live.cn \\ 2. Graduate University of Chinese Academy of Sciences, Beijing 100049, China \\ 3. Institute of BioEnergy and Bioprocess Technology, Chinese Academy of Sciences, Qingdao 266101, China \\ 4. School of Earth and Environment Sciences, the University of Adelaide, Adelaide, SA 5005, Australia
}

Received 12 October 2009; revised 13 November 2009; accepted 16 December 2009

\begin{abstract}
A phyllosphere bacterial strain EBL-06 was isolated from wheat leaves. The morphology, cultural characteristics, phospholipid fatty acids, physiological and antagonistic fungus activities of this strain were investigated. A phylogenetic tree was constructed by comparing with the published 16S rDNA sequences of the relevant bacteria. The results showed that the isolate EBL-06 was a strain of Paenibacillus polymyxa; this strain performed a high level of antagonistic fungus activity toward a broad spectrum of phytopathogens, such as Botrytis cinerea, Cladosporium cucumerinum, Fusarium spp. The isolate EBL-06 can grow well using monosodium glutamate wastewater (MGW) and potato wastewater (PW) as culture medium. The maximum yield of $6.5 \times 10^{9} \mathrm{CFU} / \mathrm{mL}$ of the isolate EBL-06 anti-fungus biocontrol agent was reached in $15 \mathrm{hr}$ cultivation at $28^{\circ} \mathrm{C}, \mathrm{pH} 6.0-7.5$ using the mixture of $\mathrm{MGW}$ and $\mathrm{PW}(1: 9)$.
\end{abstract}

Key words: phyllosphere; Paenibacillus polymyxa; wastewater; phospholipid fatty acids; biocontrol agent

DOI: $10.1016 /$ S1001-0742(09)60267-9

\section{Introduction}

Effluents from monosodium glutamate manufacturing plants possess a high strength of COD $(10,000$ $30,000 \mathrm{mg} / \mathrm{L})$, ammonium $(15,000-25,000 \mathrm{mg} / \mathrm{L})$, sulphate $(15,000-30,000 \mathrm{mg} / \mathrm{L})$ and very low $\mathrm{pH}(<2)$ (Yang et al., 2005). Effluents from potato chips industry possess a high load of starchy materials (Mishra et al., 2004). Because of the low $\mathrm{pH}$, high concentration of COD, sulfate and $\mathrm{NH}_{3}-\mathrm{N}$, the treatment of such wastewaters by conventional activated sludge processes consume a lot of energy, resulting in high treatment costs (Bai et al., 2004).

Phyllosphere microbes often have a positive influence upon plant, where they may be involved in the fixation of nitrogen, promoting the growth of plants, or the control of plant pathogens. However, some phyllosphere microbes have negative effects upon the host where plant pathogens may result in disease (Zhang et al., 2009). The high infectivity fungi may damage many economically important crops and trees, and bring a significant risk and safety concerns for food supplies. Although chemical control agents have been used world widely, the biological control agents have attracted a great $R \& D$ interest because of their potential for long-term application as environmental friendly agents (ten Hoopen and Krauss, 2006).

\footnotetext{
* Corresponding author. E-mail: zhbai@ rcees.ac.cn
}

Biocontrol agents have been used to protect plants against foliar diseases in several crops (Yuen and Schoneweis, 2007; Alvindia and Natsuaki, 2008; Perello et al., 2007). However, many of them are poor competitors for leaf surface nutrients compared with indigenous phyllosphere microbes (Zhang et al., 2008a; Lindow and Brandl, 2003, Lindow and Leveau, 2002).

Strains of Paenibacillus polymyxa have been isolated from different soils (Ash et al., 1993), rhizospheres and roots from plants cultivated all over the world, and many of them have been described as effective plant growth promoting rhizobacteria (Pichard et al., 1995; Petersen et al., 1996; Lorentz et al., 2006). However, P. polymyxa was seldom discovered in the phyllosphere before. In the present work, a strain of $P$. polymyxa EBL-06 was isolated from wheat phyllosphere, which could restrain the growth of the filamentous fungi. P. polymyxa strains have been proved to produce a wide variety of secondary metabolites, including different antibacterial and/or antifungal compounds (von der Weid et al., 2000). Therefore, the antagonistic effect of these strains upon microbial growth suggests a potential application as biological control agents. The aims of this study were to characterize the newly isolated strain of $P$. polymyxa EBL-06 and to optimize the production of the bacterium using potato wastewater (PW) and monosodium glutamate wastewater (MGW). 


\section{Materials and methods}

\subsection{Isolation and in vitro antagonist assays}

The experiment was conducted in a native field located at the Tongzhou near Beijing City, China. Wheat cultivars were planted in the field in October, 2006, watered and fertilized in accordance to local cultivation practices. Wheat phyllosphere microbes were collected in May, 2007 according to the methods described by Zhang et al. (2008b). An anti-fungi bacterial strain EBL06 was isolated on Potato-dextrose Agar (PDA) medium Petri dish, and maintained on the PDA slant tubes. The antagonistic activity of the strain was evaluated by the method of confronting cultures with the filamentous fungi (Foldes et al., 2000; Bai et al., 2008), such as Trichoderma harzimum, Botrytis cinerea, Cladosporium cucumerinum, Fusarium spp., Macrophom spp., and was modified as the following. A point of filamentous fungi was inoculated onto the center of PDA Petri dish; three points of isolation were inoculated at $2 \mathrm{~cm}$ distance from the center of the Petri dish symmetrically. The Petri dish was then incubated at $28^{\circ} \mathrm{C}$ for few days. The isolated strain was considered to be antagonistic to the filamentous fungus if it restrains the fungi growth with inhibition zone (Fig. 1).

\subsection{Physiologic and resistance to antibiotics of bacteria}

BIOLOG ECO microplates were used to analyze carbon source utilization patterns of the isolate EBL-06. The strain cultivated in the Luria-Bertani medium was collected by centrifugation and suspended with sterilized water to an OD of 0.12 at $600 \mathrm{~nm}$, inoculated into the wells of Biolog ECO plate $\left(150 \mu \mathrm{L} /\right.$ well) and incubated at $30^{\circ} \mathrm{C}$ (Holmes et al., 1994). Following $48 \mathrm{hr}$ of incubation at $28^{\circ} \mathrm{C}$, absorbance data were recorded at $590 \mathrm{~nm}$ with an ELISA Reader. The carbon was considered to be fully consumed if the $\mathrm{OD}_{590}$ of the microwell was over 0.5. The soluble starch was also test as a carbon source by the medium $(\mathrm{g} / \mathrm{L})$ : soluble starch 5.0, $\left(\mathrm{NH}_{4}\right)_{2} \mathrm{SO}_{4} 5.0, \mathrm{MgSO}_{4} \cdot 7 \mathrm{H}_{2} \mathrm{O}$
0.1, $\mathrm{KH}_{2} \mathrm{PO}_{4}$ 0.5, $\mathrm{NaCl}$ 0.5, and $\mathrm{K}_{2} \mathrm{HPO}_{4}$ 1.5.

Resistance to antibiotics was determined using standard antibiotic disks. Inhibition diameters were recorded after $24 \mathrm{hr}$ of incubation at $30^{\circ} \mathrm{C}$ under aerobic conditions. The classification of the strain, as sensitive, not sensitive or intermediate sensitive to the antibiotics, was done according to the inhibition diameters. Tests were performed in triplicates.

\subsection{PCR amplification, sequencing, and phylogenetic analysis of 16S rRNA gene}

The primer set 27F-1492R was used in PCR amplification of the 16S rRNA gene fragment of isolate EBL-06 under the conditions described by Kuklinsky et al. (2004). The 16S rDNA was sequenced by Shanghai Sangon Co. Ltd., China. Sequence similarity searches were conducted using the National Center for Biotechnology Information BLAST network service (nucleotide blast). Similar 16S rRNA gene sequences, from previously cultured bacteria, were downloaded from GenBank and manually checked for ambiguous sites using bioedit 7.0.1 software. Alignments were then performed against the $16 \mathrm{~S}$ rRNA gene sequence of isolate EBL-06, where the pair-wise deletion option for gaps was employed. The alignment data were then used for neighbour-joining analysis with 1000 bootstrap replicates (MEGA version 4.0; Arizona State University, USA) (Li et al., 2007).

\subsection{PLFA analysis}

The EBL-06 was cultured in the Luria-Bertani medium overnight and was collected into a glass tube. The total lipid fractions were then extracted following the procedure as described by Bligh and Dyer (1959). Briefly, total lipid extracts were fractioned into neutral, glyco- and polar (phospho-) lipids by silicic acid chromatography. Phospholipids (the polar fraction) were converted to fatty acid methyl esters using a mild alkaline methanolysis reaction. An internal standard, fatty acid methyl ester (FAME) of

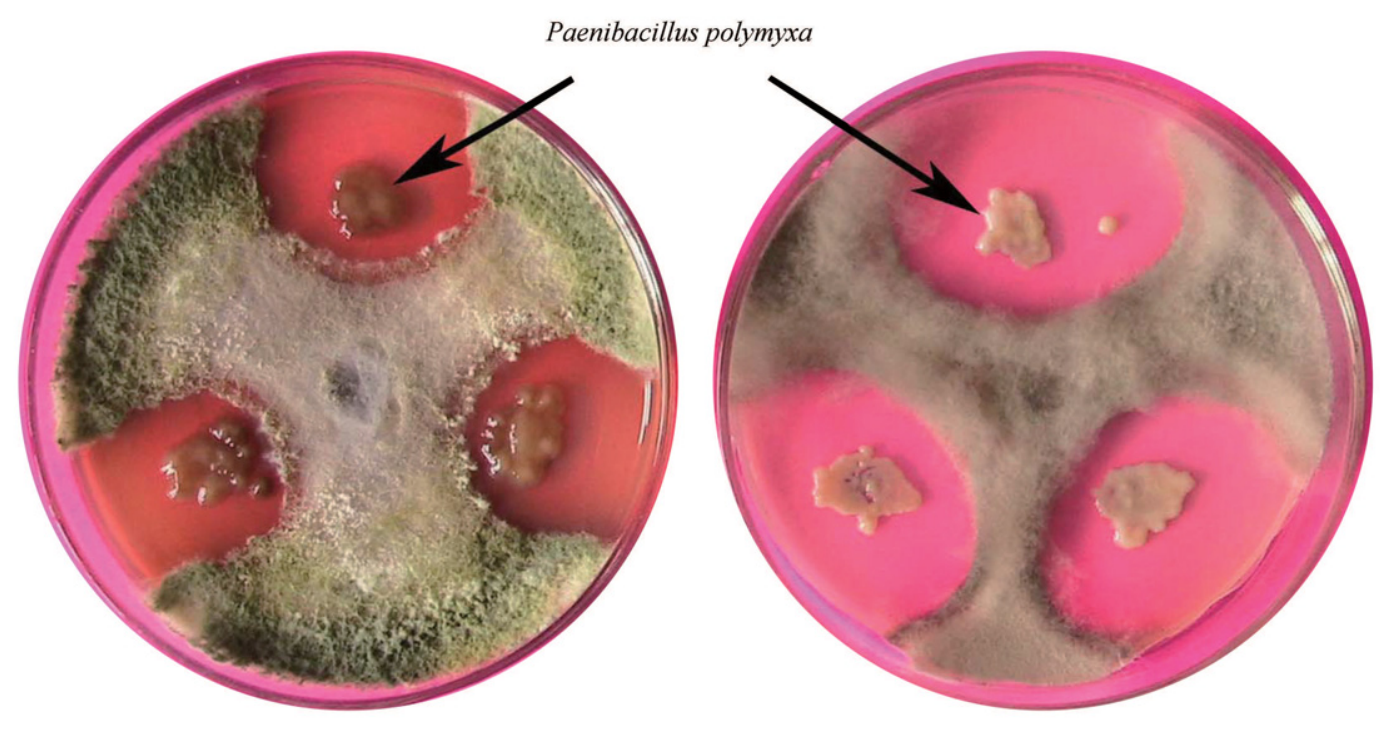

Fig. 1 Growth impact of the isolated EBL-06 on the Trichoderma harzimum (left) and Botrytis cinerea (right) at the PDA medium. 
C20:0 was added and dissolved in hexane for chromatographic analysis. FAMEs were analyzed by a GC-MS system (Hewlett Packard HP 6890, Agilent Technologies Co. Ltd., USA) equipped with a HP-5 capillary column $(30 \mathrm{~m} \times 0.32 \mathrm{~mm})$. For each sample, the abundance of individual FAMEs was calculated in relation to the internal standard and the final result was expressed in terms of peak area.

\subsection{Optimization of culture conditions}

The PW was collected from a potato starch process waste stream, Beijing, China, mainly containing $15-30 \mathrm{~g} / \mathrm{L}$ of potato starch, $20-40 \mathrm{~g} / \mathrm{L}$ of total solids, $2.0-3.9 \mathrm{~g} / \mathrm{L}$ of volatile suspended solids, $0.8-1.5 \mathrm{~g} / \mathrm{L}$ reducing sugars and $0.5-0.9 \mathrm{~g} / \mathrm{L}$ of total Kjeldahl-N. The $\mathrm{pH}$ of PW was 4.0; it was adjusted to 7.0 by $\mathrm{NaOH}$ when the PW was used as the culture medium. The starch in the PW was used as a main carbon source throughout the investigation. The MGW was obtained from Henan Lianhua Monosodium Glutamate Co., Ltd. (Zhoukou City, China), consisted of $1.20 \%$ total Kjeldahl-N, $1.17 \% \mathrm{NH}_{4}{ }^{+}, 4.06 \% \mathrm{SO}_{4}{ }^{2-}$ and $0.275 \%$ reducing sugar. Trace element components in the MGW were given as follows (mg/L): $\mathrm{Ba}, 0.932 ; \mathrm{Ca}, 389$; Co, 0.0123; Cu, 0.605; K, 259; Mg, 79.0; Pb, 0.588; Sr, 0.869; Zn, 1.80; Mn, 2.66; Fe, 4.28; Na, 794; Cr, 0.862; $\mathrm{P}, 81.4 ; \mathrm{V}, 0.0082$. The $\mathrm{pH}$ of raw MGW was 1.5 and was adjusted to 7.0 by $\mathrm{NaOH}$ when the MGW was used as the culture medium. Ammonium in the MGW was used as the main nitrogen source.

The isolate EBL-06 was grown on the PDA slants at $30^{\circ} \mathrm{C}$ for 2 days. A single clone was inoculated into 250 $\mathrm{mL}$ flask containing $100 \mathrm{~mL}$ of PDA medium at $30^{\circ} \mathrm{C}$ for $12 \mathrm{hr}$. This seed culture was used to initiate the growth in fermentation medium used in this study. The basic medium (BM) is composed of as follows ( $\mathrm{g} / \mathrm{L})$ : $\mathrm{MgSO}_{4} \cdot 7 \mathrm{H}_{2} \mathrm{O}$ $0.10, \mathrm{KH}_{2} \mathrm{PO}_{4}$ 0.50, $\mathrm{NaCl} 0.50$, and $\mathrm{K}_{2} \mathrm{HPO}_{4}$ 1.50. The fermentation was conducted in $250 \mathrm{~mL}$ Erlenmeyer flasks containing $100 \mathrm{~mL}$ medium inoculated with $5 \mathrm{~mL}$ of seed culture. Unless otherwise was stated, the agitation rate and incubation temperature were $200 \mathrm{r} / \mathrm{min}$ and $30^{\circ} \mathrm{C}$, respectively.

All experiments were conducted in duplicates and the average values are reported. Key results were repeated three times to establish their validity.

\section{Results}

\subsection{Morphology and antagonistic fungus activity of the isolate EBL-06}

Microscopic observation of the isolate EBL-06 is a mesophilic, Gram-positive and motile bacterium, and cells are rod-shaped with peritrichous flagella in overnight culture in PD medium at $30^{\circ} \mathrm{C}$ and $150 \mathrm{r} / \mathrm{min}$. The cells are found singly, double, and chains. Colonies of the strain on PDA are slightly yellow, circular, smooth, convex, semitransparent and 2-3 $\mathrm{mm}$ in diameter with an entire margin after incubation for $48 \mathrm{hr}$ at $30^{\circ} \mathrm{C}$.

EBL-06 showed a significant antagonistic activity to- wards fungal species of $C$. cucumerinum, T. harzimum, $B$. cinerea, Fusarium spp., Macrophom spp. on PDA plates. Figure 1 shows two images of the test process.

\subsection{Physiologic and resistance to antibiotics of the iso- late EBL-06}

Identified with BIOLOG-ECO plate, the isolate EBL06 could use well the following carbon sources: $\alpha$ cyclodextrin; glycogen; itaconic acid; D-galacturonic acid; 2-hydroxybenzoic acid; 4-hydroxybenzoic acid; Larginine; L-asparagine; L-serine; glycyl-L-glutamic acid; D-xylose; D-mannitol; phenylethylamine. The other carbon sources in the plate can not be fully consumed in the test process. In addition, the isolate EBL-06 could grow well using soluble starch as carbon source.

The growth behaviour of the isolate EBL-06 was studied in the presence of a range of antibiotics. The strain was susceptible to penicillin, streptomycin, kanamycin and tetracycline, also was weakly susceptible to chloramphenicol, and resistant to polymyxine and colistine.

\subsection{Phylogenetic analysis}

To analyze the phylogenetic position, the $16 \mathrm{~S}$ rDNA sequence of the isolate EBL-06 was determined, and a phylogenetic tree was constructed (Fig. 2). The sequence was deposited in the GenBank database under the accession number EF545556. The phylogenetic analysis indicated that the isolate EBL-06 is most closely related to species of $P$. polymyxa.

\subsection{PLFA analyses}

The individual PLFAs are given in Table 1. It is evident that the fatty acids 15:0, i15:0, a17:0 were the main PLFA.

\subsection{Effect of carbon sources on the isolate EBL-06 growth}

The fermentation medium contained $10 \mathrm{~mL}$ MGW, $90 \mathrm{~mL} \mathrm{BM}$, and $2 \%$ each carbon sources, including Dglucose, soluble starch, sucrose, molasses, and PW (90

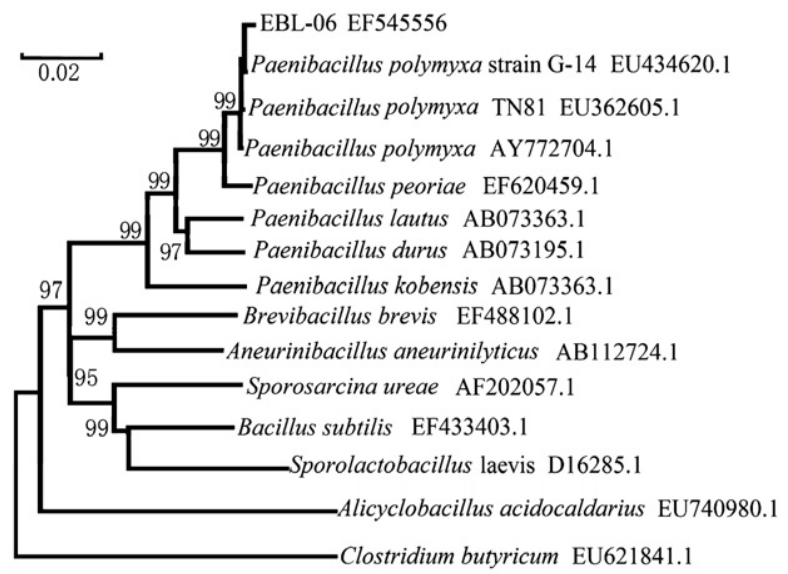

Fig. 2 Neighbor-joining trees showing the phylogenetic position of the isolate EBL-06 and its related species based on 16S rRNA gene sequences. The GenBank accession number for each microorganism used in the analysis is shown after the species name. Bootstrap values (expressed as a percentage of 1000 replications) greater than $50 \%$ are shown at the branches. 
Table 1 Composition of the EBL-06 phospholipidfatty acids

\begin{tabular}{llll}
\hline Name & $\begin{array}{l}\text { Molecular } \\
\text { weight }\end{array}$ & $\begin{array}{l}\text { Retention } \\
\text { time }(\min )\end{array}$ & $\begin{array}{l}\text { Percentage } \\
(\%)\end{array}$ \\
\hline 14:0 & 242 & 15.14 & 0.71 \\
$15: 0$ & 256 & 16.75 & 13.36 \\
i15:0 & 256 & 16.90 & 50.93 \\
$16: 0$ & 270 & 18.38 & 6.88 \\
$16: 1 \omega 9 t$ & 268 & 18.66 & 0.11 \\
i16:0 & 270 & 18.98 & 4.09 \\
$17: 0$ & 284 & 19.99 & 4.55 \\
a17:0 & 284 & 20.13 & 19.08 \\
$18: 0$ & 298 & 22.34 & 0.45 \\
$19: 0$ & 312 & 24.00 & 0.78 \\
\hline
\end{tabular}

$\mathrm{mL}$, the carbon source equal to $2 \mathrm{~g}$ starch, no BM). After inoculation with $2 \mathrm{~mL}$ inoculum, the medium was incubated at $30^{\circ} \mathrm{C}$ for $20 \mathrm{hr}$. The effect of carbon sources on the production of the isolate EBL-06 are presented in Fig. 3. It was found that molasses were the most efficient carbon sources for the production of strain. Comparing with the molasses, PW are the most suitable carbon source due to the low cost.

\subsection{Effect of nitrogen sources on the isolate EBL-06 growth}

The fermentation medium contained $90 \mathrm{~mL} \mathrm{PW}$ as carbon source, $10 \mathrm{~mL} \mathrm{BM}$, and $0.5 \%$ different nitrogen sources, which were ammonium sulfate, water, potassium nitrate, corn steep liquor and $\mathrm{MGW}(10 \mathrm{~mL}$, the nitrogen source equal to $0.5 \mathrm{~g}\left(\mathrm{NH}_{4}\right)_{2} \mathrm{SO}_{4}$, no $\left.\mathrm{BM}\right)$. A control experiment was conducted without addition of nitrogen source. After inoculation with $2 \mathrm{~mL}$ inoculum, the medium was incubated at $30^{\circ} \mathrm{C}$ for $20 \mathrm{hr}$. The results of impact of nitrogen sources on the production of isolate EBL-06 are presented in Fig. 4. It was found that corn steep liquor and MGW were the most efficient nitrogen sources for the production of strain. Comparing with the corn steep liquor, MGW are the most suitable nitrogen source due to the low cost.

\subsection{Effect of pH on the isolate EBL-06 growth}

The fermentation medium contained $10 \mathrm{~mL}$ MGW, $90 \mathrm{~mL}$ PW. After inoculation with $2 \mathrm{~mL}$ inoculum, the medium was incubated at pH 5.5, 6.0, 6.5, 7.0, 7.5 and 8.0 respectively. The isolate EBL-06 production at different

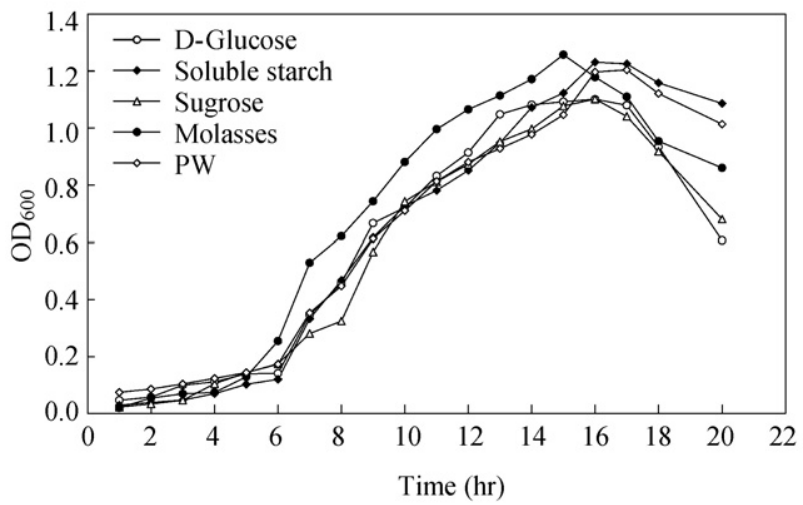

Fig. 3 Effect of different carbon sources on the isolate EBL-06 growth. PW: potato wastewater.

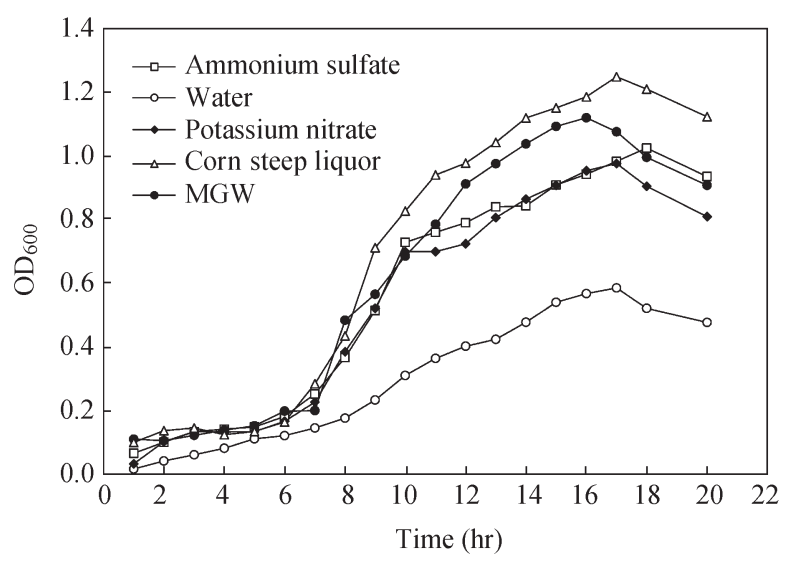

Fig. 4 Effect of different nitrogen sources on the isolate EBL-06 growth. MGW: monosodium glutamate wastewater.

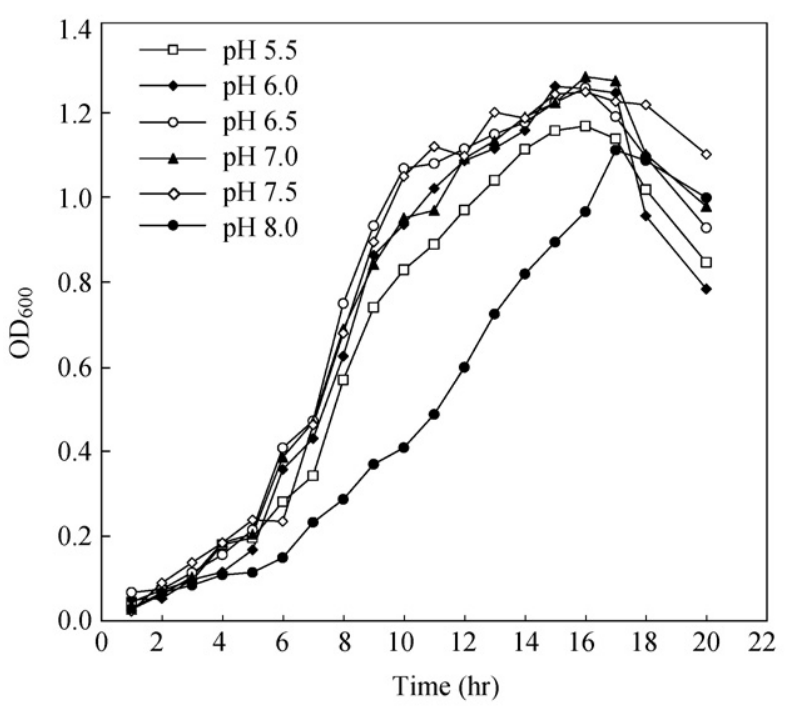

Fig. 5 Effect of initial culture medium $\mathrm{pH}$ on the isolate EBL-06 growth.

$\mathrm{pH}$ is shown in Fig. 5. The highest yield could be given at $\mathrm{pH}$ 6.0-7.5 after $15 \mathrm{hr}$ fermentation. Consequently, $\mathrm{pH}$ 7.0 was selected in the following experiment.

\subsection{Effect of culture temperature on the isolate EBL-06 production}

The fermentation medium contained $10 \mathrm{~mL}$ MGW, 90 $\mathrm{mL}$ PW. After inoculation with $2 \mathrm{~mL}$ inoculum, the medium was incubated at $24,28,32,36$ and $40^{\circ} \mathrm{C}$, respectively. The time courses of the isolate EBL-06 production at different temperatures are shown in Fig. 6. The maximum yield of $6.5 \times 10^{9} \mathrm{CFU} / \mathrm{mL}$ was reached at $28-32^{\circ} \mathrm{C}$ after $15 \mathrm{hr}$ fermentation.

\section{Discussion}

P. polymyxa endospore was reported to be resistant to desiccation, heat, and UV irradiation, and have excellent biochemical characteristics that allow for further formulation and commercialization procedures. Previous studies have shown that strains of $P$. polymyxa can produce different peptide antimicrobial substances (Rosado 


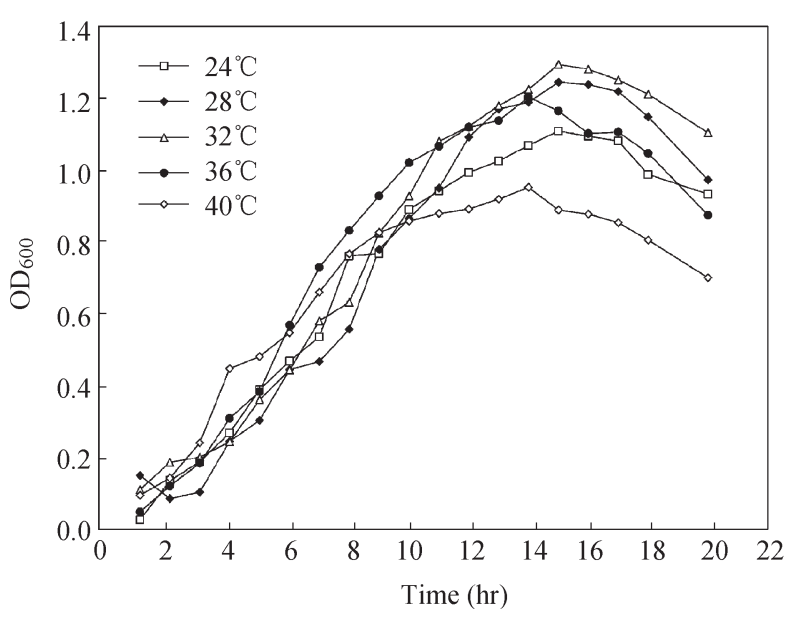

Fig. 6 Effect of culture temperature on the isolate EBL-06 growth.

and Seldin, 1993; Piuri et al., 1998; Dijksterhuis et al., 1999; Seldin et al., 1999). The peptide metabolites are generally classified into two groups according to their antimicrobial activities. The first group includes the polypeptins, polymyxins, jolipeptin, gavaserin, and saltavalin, which showed antibacterial activity against both Gram-negative and gram-positive bacteria. The second group consists of a single family of closely related peptides variously designated gatavalin, fusaricidins, all of which contain an unusual fatty acid side chain, 15-guanidino3-hydroxypentadecanoic acid (Raza et al., 2009). As a phyllosphere isolate, $P$. polymyxa EBL-06 could be suitable to survive in the phyllosphere conditions; the antagonistic fungi ability also give them a growth advantage in the competitive environment. $P$. polymyxa EBL-06 showed a significant antagonistic activity towards all the filamentous fungi tested. It will be used as a potential biocontrol agent for protecting plant against fungal disease in further study.

MGW is one of the most intractable wastewater because of its high strength of COD, ammonium and sulphate (Yang et al., 2005). PW is also a high concentration of COD wastewater. A few studies have focused on the utilization of such high concentration of organic matter wastewater (Bai et al., 2004; Mishra et al., 2004; Huang et al., 2005). As far as the authors are aware, no article has been published on utilization of both MGW and PW in one process. In the present study, the isolate EBL-06 could use well the starch in the PW as the main carbon source, and ammonium in the MGW as the main nitrogen source. In addition, the nutrient and trace element components in the wastewaters are also suitable for the isolate EBL-06 growth. Compared with other culture media, the mixture of PW and MGW is the most suitable for the biocontrol agent production from the economic and environmental point of view.

$P$. polymyxa has also been isolated from several places such as food, rhizosphere, poultry production environments, and soils; and most of them can restrain fungal pathogen growth (He et al., 2007; Raza et al., 2009; Svetoch et al., 2005). Further studies will investigate the anti-fungal pathogen activity of the isolate EBL-06 both in phyllosphere and in rhizosphere by field trials. Further understanding of the survival strategy of the isolate EBL06 in phyllosphere might improve the efficiency of the biological treatments and also lead to enhanced yields of agricultural crops.

\section{Conclusions}

A newly isolated $P$. polymyxa EBL-06 from wheat phyllosphere can be used as a nonchemical alternative biocontrol agent against plant disease caused by fungal pathogen. A novel process for economical production of $P$. polymyxa biocontrol agent was developed using MGW and PW. It is feasible to develop a hybrid biotechnological process, integrating the production of environmental friendly biocontrol agent with the treatment of intractable wastewater.

\section{Acknowledgments}

This work was supported by the National Natural Science Foundation of China (No. 30600082), the Knowledge Innovation Program of Chinese Academy of Sciences (No. KSCX2-YW-G-054-2) and the Key Technologies R\&D Program of China (No. 2008BADA7B01). We are grateful to Mr. Lidong Gao and Yang Zhou from Henan Lianhua Monosodium Glutamate Co., Ltd., for their help in MGW supplying.

\section{References}

Alvindia D G, Natsuaki K T, 2008. Evaluation of fungal epiphytes isolated from banana fruit surfaces for biocontrol of banana crown rot disease. Crop Protection, 27(8): 12001207.

Ash C, Priest F G, Collins M D, 1993. Molecular identification of rRNA group 3 bacilli (Ash, Farrow, Wallbanks and Collins) using a PCR probe test. Antone Van Leeuwenhoek International Journal of General and Molecular Microbiology, 64(3-4): 253-260.

Bai Z H, Zhang H X, Qi H Y, Peng X W, Li B J, 2004. Pectinase production by Aspergillus niger using wastewater in solid state fermentation for eliciting plant disease resistance. Bioresource Technology, 95(1): 49-52.

Bai Z H, Jin B, Li Y J, Chen J, Li Z M, 2008. Utilization of winery wastes for Trichoderma viride biocontrol agent production by solid state fermentation. Journal of Environmental Sciences, 20(3): 353-358.

Bligh E, Dyer W J, 1959. A rapid method of total lipid extraction and purification. Canadian Journal of Biochemistry and physiology, 37(1): 911-917.

Dijksterhuis J, Sander M, Gorris L G M, Smid E J, 1999. Antibiosis plays a role in the context of direct interaction during antagonism of Paenibacillus polymyxa towards Fusarium oxysporum. Journal of Applied Microbiology, 86(1): 1321.

Foldes T, Banhegyi I, Herpai Z, Varga L, Szigeti J, 2000. Isolation of Bacillus strains from the rhizosphere of cereals and in vitro screening for antagonism against phytopathogenic, food-borne pathogenic and spoilage micro-organisms. Journal of Applied Microbiology, 89(5): 840-846.

He Z G, Kisla D, Zhang L W, Yuan C H, Green-Church K B, 
Yousef A E, 2007. Isolation and identification of a Paenibacillus polymyxa strain that coproduces a novel lantibiotic and polymyxin. Applied and Environmental Microbiology, 73(1): 168-178.

Holmes B, Costas M, Ganner M, ON S L W, Stevens M, 1994. Evaluation of Biolog system for identification of some Gram-negative bacteria of clinical importance. Journal of Clinical Microbiology, 32(8): 1970-1975.

Kuklinsky S J, Araujo W L, Mendes R, Geraldi I O, Pizzirani K A A, Azevedo J L, 2004. Isolation and characterization of soybean-associated bacteria and their potential for plant growth promotion. Environmental Microbiology, 6(12): 1244-1251.

Huang L P, Jin B, Lant P, 2005. Direct fermentation of potato starch wastewater to lactic acid by Rhizopus oryzae and Rhizopus arrhizus. Bioprocess and Biosystems Engineering, 27(4): 229-238.

Li X, Ma X H, Zhao Y H, Jia X M, Kai L, Guo K P et al., 2007. Isolation and characterization of a new bacterium capable of biotransforming cis-epoxysuccinic acid to $\mathrm{D}(-)$-tartaric acid. FEMS Microbiol Letters, 267(2): 214-220.

Lindow S E, Brandl M T, 2003. Microbiology of the phyllosphere. Applied and Environmental Microbiology, 69(4): 1875-1883.

Lindow S E, Leveau J H, 2002. Phyllosphere microbiology. Current Opinion in Biotechnology, 13(3): 238-243.

Lorentz R H, Artico S, da Silveira B A, Einsfeld A, Corcao G, 2006. Evaluation of antimicrobial activity in Paenibacillus spp. strains isolated from natural environment. Letters in Applied Microbiology, 43(5): 541-547.

Mishra B K, Arora A, Lata, 2004. Optimization of a biological process for treating potato chips industry wastewater using a mixed culture of Aspergillus foetidus and Aspergillus niger. Bioresource Technology, 94(1): 9-12.

Piuri M, Sanchez-Rivas C, Ruzal S M, 1998. A novel antimicrobial activity of a Paenibacillus polymyxa strain isolated from regional fermented sausages. Letters in Applied Microbiology, 27(1): 9-13

Perello A, Moreno V, Monaco C, Simon M R, 2007. Effect of Trichoderma spp. isolates for biological control of tan spot of wheat caused by Pyrenophora tritici-repentis under field conditions in Argentina. BioControl, 53(6): 895-904.

Petersen D J, Srinivasan M, Chanway C P, 1996. Bacillus polymyxa stimulates increased Rhizobium etli populations and nodulation when co-resident in the rhizosphere of Phaseolus vulgaris. FEMS Microbiology Letters, 142(2-3): 271-276.

Pichard B, Larue J P, Thouvenot D, 1995. Gavaserin and saltavalin, new peptide antibiotics produced by Bacillus polymyxa. FEMS Microbiology Letters, 133(3): 215-218.

Raza W, Yang X, Wu, H, Wang Y, Xu Y, Shen Q, 2009. Isolation and characterisation of fusaricidin-type compoundproducing strain of Paenibacillus polymyxa SQR-21 active against Fusarium oxysporum f. sp nevium. European Journal of Plant Pathology, 125(3): 471-483.

Rosado A S, Seldin L, 1993. Production of a potentially novel anti-microbial substance by Bacillus polymyxa. World Journal of Microbiology and Biotechnology, 9(5): 521-528.

Seldin L, Azevedo F S, Alviano D S, Alviano C S, Bastos M C F, 1999. Inhibitory activity of Paenibacillus polymyxa SCE2 against human pathogenic micro-organisms. Letters in Applied Microbiology, 28(6): 423-427.

Svetoch E A, Stern N J, Eruslanov B V, Kovalev Y N, Volodina L I, Perelygin V V et al., 2005. Isolation of Bacillus circulans and Paenibacillus polymyxa strains inhibitory to Campylobacter jejuni and characterization of associated bacteriocins. Journal of Food Protection, 68(1): 11-17.

ten Hoopen G M, Krauss U, 2006. Biology and control of Rosellinia bunodes, Rosellinia necatrix and Roselliia pepo: A review. Crop Protection, 25(2): 89-107.

von der Weid I, Paiva E, Nobrega A, van Elsas J D, Seldin L, 2000. Diversity of Paenibacillus polymyxa strains isolated from the rhizosphere of maize planted in Cerrado soil. Research in Microbiology, 151(5): 369-381.

Yang Q, Yang M, Zhang S, Lv W, 2005. Treatment of wastewater from a monosodium glutamate manufacturing plant using successive yeast and activated sludge systems. Process Biochemistry, 40(7): 2483-2488.

Yuen G Y, Schoneweis S D, 2007. Strategies for managing Fusarium head blight and deoxynivalenol accumulation in wheat. International Journal of Food Microbiology, 119(12): 126-130.

Zhang B G, Bai Z H, Hoefel D, Tang L, Yang Z G, Zhuang G Q et al., 2008a. Assessing the impact of the biological control agent Bacillus thuringiensis on the indigenous microbial community within the pepper plant phyllosphere. FEMS Microbiology Letters, 284(1): 102-108.

Zhang B G, Zhang H X, Jin B, Tang L, Yang J Z, Li B J et al., 2008b. Effect of cypermethrin insecticide on the microbial community in cucumber phyllosphere. Journal of Environmental Sciences, 20(11): 1356-1362.

Zhang B G, Bai Z H, Hoefel D, Tang L, Wang X Y, Li B J et al., 2009. Impacts of cypermethrin pesticide application on the non-target microbial community within the pepper plant phyllosphere. Science of the Total Environment, 407(6): 1915-1922. 